\title{
Predictor Analysis of Mid-Term Left Atrial Reverse Remodeling after Mitral Valve Surgery*
}

\author{
Kaoru Matsuura\#, Kenji Mogi, Manabu Sakurai, Tomonori Kawamura, Yoshiharu Takahara \\ Funabashi Municipal Medical Center, Department of Cardiovascular Surgery, Chiba, Japan \\ Email: "km4717jp@yahoo.co.jp
}

Received February 4, 2013; revised April 10, 2013; accepted May 5, 2013

Copyright (C) 2013 Kaoru Matsuura et al. This is an open access article distributed under the Creative Commons Attribution License, which permits unrestricted use, distribution, and reproduction in any medium, provided the original work is properly cited.

\begin{abstract}
Objective: The aim of this study was to predict mid-term left atrial reverse remodeling after mitral valve surgery. Patients and Methods: Echocardiographic data was obtained preoperatively and at follow-up from 105 patients who underwent mitral valve surgery. Left atrial volume (LAV) was decreased by $>30 \%$ from baseline in 43 patients (group A), but not in 62 patients (group B). Results: Patients in group A were younger $(p=0.0029)$. Male was more $(p=0.05)$ and prosthesis size was bigger in group A $(\mathrm{p}=0.005)$. Only age was a predictor of left atrial reverse remodeling in a logistic regression model $(\mathrm{OR}=0.93,95 \%$ CI $0.88-0.99 ; \mathrm{p}=0.03)$. Late mean trans-mitral pressure gradient was lower in group A than in group $B(p=0.01)$. There was a weak correlation between the change in left ventricular end-diastolic diameter (LVDd) and LAV (correlation coefficient 0.27, 95\% CI $0.07-0.45 ; \mathrm{p}=0.008$ ). Survival and freedom from major adverse cardiac events did not differ between the groups $(\mathrm{p}=0.31$ and $\mathrm{p}=0.87$ by log-rank test). Conclusions: Age was the only predictor of left atrial reverse remodeling. There was a weak correlation between changes in LVDd and LAV.
\end{abstract}

Keywords: Atrium; Mitral Valve; Outcomes

\section{Introduction}

Left ventricular remodeling, enlargement of the left ventricle, is a well-known consequence of left ventricular dysfunction [1]. Medical treatment of chronic left ventricular heart failure is thought to cause left ventricular reverse remodeling, which is a reduction in the size of the left ventricle. Not only medical treatment, but also mitral valve surgery can cause left ventricular reverse remodeling. Left ventricular reverse remodeling can lead to better clinical outcomes. In contrast, changes in the size of the left atrium have not been as well studied. Left atrial enlargement is associated with adverse cardiovascular outcomes, including left ventricular dysfunction, atrial fibrillation, and stroke [2,3]. Causes of left atrial enlargement are thought to include atrial fibrillation and mitral valve disease [4].

Patients with severe long-standing chronic mitral valve disease or atrial fibrillation can experience alterations in the size of the left atrium, a process known as left atrial remodeling [5]. For example, left atrial remodeling can be caused by pressure overload in association with mitral

"Conflict of Interest: None.

\#Corresponding author. stenosis or volume overload in association with mitral regurgitation [4]. Left atrial remodeling includes left atrial dilatation, left atrial dysfunction, and left atrial failure $[6,7]$. Since mitral valve surgery can correct anti-physiological conditions in the mitral valve, it can also cause left atrial reverse remodeling.

In this study, we aimed to identify predictors of midterm left atrial reverse remodeling after mitral valve surgery, and to compare left atrial reverse remodeling and left ventricular reverse remodeling.

\section{Patients and Methods}

A total of 105 mitral valve surgeries were performed between 2006 and 2009 at our institution and were included in this study. Initial data were collected from patient medical records. Full Doppler echocardiography was performed preoperatively and more than 6 months postoperatively for all patients.

Left ventricular end-systolic diameter (LVDs), left ventricular end-diastolic diameter (LVDd), and end-diastolic septal and posterior wall thickness were measured in the parasternal view using 2D-guided M-Mode echocardiography in accordance with the recommendations for 
chamber quantification [8]. Left ventricular ejection fraction (EF) and mitral valve area were also recorded. Left atrial volume was measured using the prolate ellipse method [9]. The postoperative peak and mean diastolic pressure gradient across the mitral valve and tricuspid valve were calculated from the apical 4-chamber view.

Institutional approval for this study was obtained, and each patient provided informed consent before participation. Patients in whom the mid-term left atrial volume was decreased by $>30 \%$ from baseline were classified as group $A$, and those in whom no such change was seen were classified as group $\mathrm{B}$. We then compared the background, outcomes, and echocardiographic data from the patients in these 2 groups.

The primary endpoint was late survival, and the secondary endpoint was the incidence of major adverse cardiac events (MACE) and neurological events. MACE was defined as cardiac events that required re-admission. Follow-up was conducted periodically on a structured outpatient clinic basis, along with a review of hospital healthcare records and echocardiographic documentation.

\section{Surgical Procedures}

All surgeries were performed under general anesthesia. Anesthetic techniques and medications were similar in all patients. Anesthesia was induced with fentanyl, propofol, and neuromuscular paralytic drugs and was maintained by inhalation anesthesia using the same drugs. All mitral valve surgeries were performed with moderate hypothermia and antegrade cold cardioplegic solution. Bypass management included membrane oxygenators, arterial line filters, use of a roller pump, a nonpulsatile flow of 2.4 $\mathrm{l} / \mathrm{min} / \mathrm{m}^{2}$ and a target mean arterial pressure $>50 \mathrm{~mm} \mathrm{Hg}$. MAZE procedures were performed using a radiofrequency ablation device.

\section{Statistical Analysis}

All data were reviewed retrospectively. All continuous values are expressed as mean $\pm \mathrm{SD}$. A comparative analysis of the 2 different patient groups was performed. Differences were analyzed using univariate analyses (the $\chi^{2}$ test, the two-tailed t test, and the Mann-Whitney U test as appropriate). The Kaplan-Meier method was used to assess the time-related outcomes of survival and freedom from MACE. Survival curves were compared using the log-rank test; $\mathrm{p}<0.05$ was used to indicate significance.

\section{Results}

Overall, left atrial volume decreased from $108.6 \pm 72.6$ $\mathrm{mL}$ (preoperative period) to $79.4 \pm 53.8 \mathrm{~mL}$ (long-term follow-up). Mid-term left atrial volume was decreased by $>30 \%$ from baseline in 43 patients (group A), but no such changes were observed in 62 patients (group B). The average follow-up was $18.0 \pm 11.1$ months, and the average duration between surgery and follow-up echocardiogramphy was $16.2 \pm 1.33$ months. Tables 1 and 2 show preoperative and perioperative variables, respectively. Patients in group A were younger $(64.1 \pm 7.4$ years $)$ than those in group $B(69.3 \pm 7.7$ years; $p=0.0029)$. The proportion of males was also higher in group A (67.4\%) compared with group B (46.7\%), and the prosthesis was larger in group A $(27.8 \pm 1.7 \mathrm{~mm})$ than group B $(26.7 \pm$ $1.7 \mathrm{~mm})(\mathrm{p}=0.005)$. The proportion of patients with a pathological disorder, mainly mitral regurgitation, did not differ between the groups (A, 88.4\% vs. B, 82.3\%; $\mathrm{p}$ $=0.42$ ), nor did the proportion requiring valve repair $(A$, $11.6 \%$ vs. $\mathrm{B}, 8.1 \%$; $\mathrm{p}=0.73)$. A mechanical valve was used in $65.8 \%$ of patients in group $\mathrm{A}$ and $31.6 \%$ of patients in group $B(p=0.005)$. There was no betweengroup difference in the prevalence of preoperative atrial fibrillation (A, 48.8\% vs. B, 48.4\%; p = 0.99), performance of MAZE procedures (A, 25.6\% vs. B, 16.1\%; p = 0.32 ), or late atrial fibrillation (A, 32.6\% vs. B, 33.0\%). Table 3 shows the results of a multivariate predictor analysis of mid-term left atrial reverse remodeling. Factors with $\mathrm{p}<0.05$ in the univariate analysis were included in the multivariate analysis. Preoperative atrial fibrillation, which has been reported to be a factor causing left atrial remodeling, was also included in the multivariate analysis. Only age was found to be a predictor of left atrial reverse remodeling in the logistic regression

Table 1. Preoperative variables.

\begin{tabular}{lccc}
\hline & $\begin{array}{c}\text { Group A } \\
(\mathrm{n}=43)\end{array}$ & $\begin{array}{c}\text { Group B } \\
(\mathrm{n}=62)\end{array}$ & $\mathrm{p}$ \\
\hline Age (years) & $64.1 \pm 9.4$ & $69.3 \pm 1.1$ & 0.003 \\
Sex (\% male) & $29(67.4 \%)$ & $29(46.7 \%)$ & 0.05 \\
Body weight (kg) & $55.9 \pm 10.6$ & $55.7 \pm 11.4$ & 0.95 \\
Height (cm) & $161 \pm 10.8$ & $158 \pm 10.1$ & 0.40 \\
Body surface area (m²) & $1.58 \pm 0.19$ & $1.53 \pm 0.27$ & 0.30 \\
Emergency (\%) & $1(2.3 \%)$ & $3(4.8 \%)$ & 0.64 \\
Preoperative NYHA class & $2.3 \pm 0.9$ & $2.3 \pm 1.0$ & 0.94 \\
Coronary artery disease (\%) & $5(11.6 \%)$ & $10(16.1 \%)$ & 0.58 \\
Hypertension (\%) & $14(32.6 \%)$ & $25(40.3 \%)$ & 0.54 \\
Diabetes mellitus (\%) & $5(11.6 \%)$ & $8(12.9 \%)$ & 0.99 \\
Hyperlipidemia (\%) & $12(27.9 \%)$ & $11(17.7 \%)$ & 0.24 \\
Chronic renal failure (\%) & 0 & $5(8.0 \%)$ & 0.08 \\
Peripheral vascular disease (\%) & 0 & $2(3.2 \%)$ & 0.51 \\
Preoperative atrial fibrillation (\%) & $21(48.8 \%)$ & $30(48.3 \%)$ & 0.99 \\
Mitral regurgitation (\%) & $38(88.4 \%)$ & $51(82.3 \%)$ & 0.65 \\
\hline
\end{tabular}


Table 2. Perioperative variables.

\begin{tabular}{lccc}
\hline & $\begin{array}{c}\text { Group A } \\
(\mathrm{n}=43)\end{array}$ & $\begin{array}{c}\text { Group B } \\
(\mathrm{n}=62)\end{array}$ & $\mathrm{p}$ \\
\hline Valve repair (\%) & $5(11.6 \%)$ & $5(8.0 \%)$ & 0.74 \\
Prosthesis size (mm) & $27.8 \pm 1.7$ & $26.7 \pm 1.7$ & 0.005 \\
Operation time (minutes) & $202 \pm 58$ & $220 \pm 78$ & 0.22 \\
ECC time (minutes) & $121 \pm 49$ & $113 \pm 33$ & 0.33 \\
ACC time (minutes) & $84.2 \pm 24.9$ & $85.6 \pm 37.4$ & 0.82 \\
Blood transfusion (\%) & $17(39.5 \%)$ & $29(46.8 \%)$ & 0.43 \\
Mechanical valve (\%) & $1(2.3 \%)$ & $10(16.1 \%)$ & 0.30 \\
MAZE procedure (\%) & $10(23.3 \%)$ & $11(17.7 \%)$ & 0.32 \\
Concomitant CABG & $9(20.9 \%)$ & $3(4.8 \%)$ & 0.35 \\
Concomitant AVR & $10(23.3 \%)$ & $18(29.0 \%)$ & 0.65 \\
Concomitant tricuspid surgery & $13(30.2 \%)$ & $23(37.1 \%)$ & 0.31 \\
Chordal preservation & $33(76.7 \%)$ & $50(80.6 \%)$ & 0.73 \\
LV reconstruction & $2(4.7 \%)$ & $2(3.2 \%)$ & 0.99 \\
\hline
\end{tabular}

Table 3. Multivariate analysis.

\begin{tabular}{cccc}
\hline & p & Hazard ratio & $95 \%$ CI \\
\hline Age & 0.04 & 0.94 & $0.88-0.99$ \\
Sex (male) & 0.36 & 1.58 & $0.58-4.23$ \\
Prosthesis size & 0.64 & 1.24 & $0.49-3.14$ \\
Preoperative atrial fibrillation & 0.25 & 1.19 & $0.88-1.60$ \\
\hline
\end{tabular}

model (OR $=0.93,95 \%$ CI $0.88-0.99 ; \mathrm{p}=0.03)$. Preoperative and follow-up echocardiographic data are shown in Table 4. Patients in group A had a lower pressure gra-

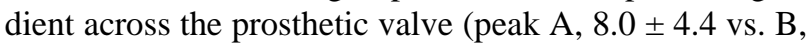
$10.3 \pm 4.2$, $\mathrm{p}=0.01$; mean $\mathrm{A}, 3.0 \pm 1.3$ vs. $\mathrm{B}, 3.9 \pm 1.9$, $\mathrm{p}$ $=0.01$ ). Preoperative echocardiography data showed that the preoperative LVDd was larger (A, $55.9 \pm 8.6 \mathrm{~mm}$ vs. $\mathrm{B}, 51.3 \pm 9.5 \mathrm{~mm} ; \mathrm{p}=0.02$ ), the preoperative transpulmonary gradient was higher (A, $36.8 \pm 16.6 \mathrm{~mm} \mathrm{Hg}$ vs. $\mathrm{B}, 31.0 \pm 11.3 \mathrm{~mm} \mathrm{Hg} ; \mathrm{p}=0.04)$, and the preoperative left atrial volume was larger (A, $129.0 \pm 87.1 \mathrm{~mm}$ vs. B, $94.5 \pm 57.2 \mathrm{~mm} ; \mathrm{p}=0.02$ ) among patients in group $\mathrm{A}$ compared with those in group B. Mid-term echocardiography showed that the peak (A, $8.1 \pm 4.1 \mathrm{~mm} \mathrm{Hg}$ vs. B, $10.3 \pm 4.2 \mathrm{~mm} \mathrm{Hg} ; \mathrm{p}=0.01)$ and mean $(\mathrm{A}, 2.9 \pm 1.2 \mathrm{~mm}$ Hg vs. $B, 3.9 \pm 1.8 \mathrm{~mm} \mathrm{Hg}$; $=0.01$ ) trans-mitral pressure gradient was lower among patients in group A compared with those in group B. The changes in LVDd and LVDs (mid-term/preoperative \%) were different between the groups (Dd A, $85 \pm 8 \%$ vs. B, $94 \pm 12 \%$, p = 0.0007; Ds: A, $90 \pm 17 \%$ vs. B, $98 \pm 19 \%$, $\mathrm{p}=0.04)$. There was a weak correlation between the changes in Dd and left atrial volume (correlation coefficient $0.27,95 \%$ CI 0.07 0.45; $\mathrm{p}=0.008$ ) (Figure 1). Clinical outcomes are shown in Table 5. The survival rate and freedom from MACE were not significantly different between the groups $(\mathrm{p}=$ 0.31 and $p=0.87$ by log-rank test) (Figures 2 and 3 ).

\section{Discussion}

Left atrial size has traditionally been thought to be important in patients with mitral valve pathology because it reflects the history (severity and duration) of mitral valve

Table 4. Echocardiographic data.

\begin{tabular}{lccc}
\hline Preoperative & $\begin{array}{c}\text { Group A } \\
(\mathrm{n}=43)\end{array}$ & $\begin{array}{c}\text { Group B } \\
(\mathrm{n}=62)\end{array}$ & $\mathrm{p}$ \\
\hline LVDd & $55.9 \pm 8.9$ & $51.3 \pm 9.5$ & 0.02 \\
LVDs & $39.1 \pm 10.9$ & $35.5 \pm 9.5$ & 0.08 \\
LVEF & $56.0 \pm 14.2$ & $56.5 \pm 12.9$ & 0.85 \\
PG across TV & $36.8 \pm 16.6$ & $31.0 \pm 11.3$ & 0.05 \\
LA volume & $129.0 \pm 87.1$ & $94.5 \pm 57.1$ & 0.02 \\
\hline Mid-term & & & \\
\hline LVDd & $46.9 \pm 7.5$ & $47.3 \pm 8.8$ & 0.81 \\
LVDs & $33.6 \pm 9.2$ & $34.4 \pm 10.9$ & 0.70 \\
LVEF & $54.2 \pm 11.8$ & $53.6 \pm 12.7$ & 0.82 \\
PG across TV & $22.4 \pm 8.4$ & $25.3 \pm 6.7$ & 0.01 \\
Peak PG across MV & $8.0 \pm 4.4$ & $10.3 \pm 4.2$ & 0.01 \\
Mean PG across MV & $3.0 \pm 1.3$ & $3.9 \pm 1.9$ & 0.01 \\
MV area & $2.6 \pm 0.6$ & $2.4 \pm 0.6$ & 0.09 \\
LA volume & $67.7 \pm 54.3$ & $87.5 \pm 52.4$ & 0.06 \\
\hline $\begin{array}{l}\text { Changes of chambers } \\
\text { (Mid-term/pre, \%) }\end{array}$ & & & \\
\hline LVDd & $85.2 \pm 8.8$ & $93.5 \pm 12.5$ & 0.0007 \\
LVDs & $52.3 \pm 12.1$ & $94.8 \pm 21.6$ & 0.0001 \\
\hline LA volume & & & \\
\hline & & $98.1 \pm 19.7$ & 0.04 \\
\hline
\end{tabular}

Correlation between changes of LA volume and change of LVDd

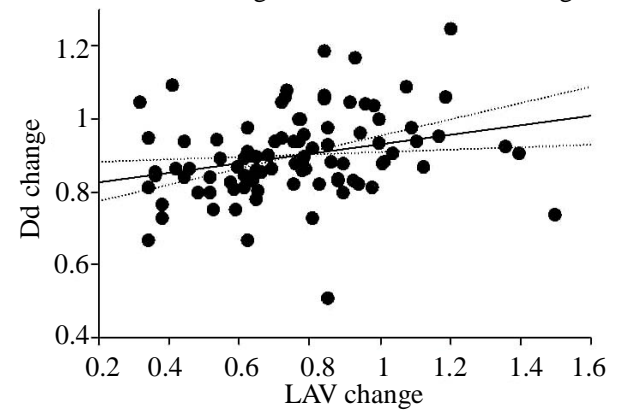

Dd change $=0.802+0.129 *$ LAV change; $\mathrm{R}^{\wedge} 2=0.075$

Figure 1. Correlation between changes in left atrial volume and LVDd. 
Table 5. Outcomes.

\begin{tabular}{lccc}
\hline & Group A (n=43) & Group B (n=62) & $\mathrm{p}$ \\
\hline Re-exploration & $1(2.3 \%)$ & $3(4.8 \%)$ & 0.64 \\
Postop renal failure & $2(4.7 \%)$ & $5(8.0 \%)$ & 0.70 \\
Postop atrial fibrillation & $11(25.6 \%)$ & $18(29.0 \%)$ & 0.83 \\
Postop LOS & $1(2.3 \%)$ & $4(6.5 \%)$ & 0.65 \\
Postop LV rupture & $1(2.3 \%)$ & 0 & 0.41 \\
Postop NYHA & $1.00 \pm 0.37$ & $1.06 \pm 0.41$ & 0.39 \\
Hospital mortality & 0 & $2(3.2 \%)$ & 0.51 \\
Late mortality & $2(4.7 \%)$ & $5(8.2 \%)$ & 0.70 \\
Late MACE & $3(7.0 \%)$ & $3(4.8 \%)$ & 0.69 \\
Late atrial fibrillation & $14(32.6 \%)$ & $21(33.0 \%)$ & 0.83 \\
\hline
\end{tabular}

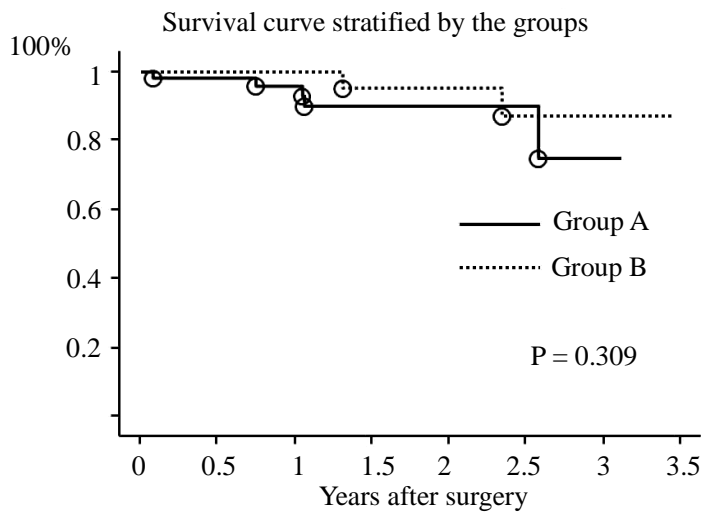

Figure 2. Survival curve.

Freedom from MACE stratified by the groups

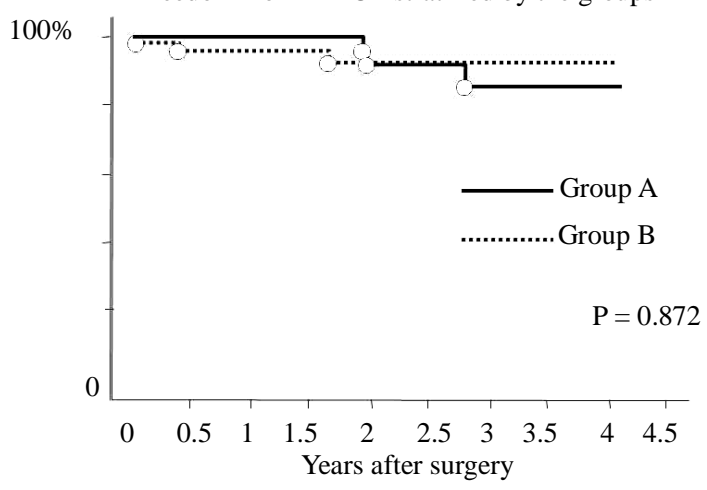

Figure 3. Freedom from MACE.

disease [4]. Atrial enlargement has also been considered to occur as a consequence of atrial fibrillation [5]. While left ventricular reverse remodeling after mitral valve surgery has been widely reported, left atrial remodeling has not been well studied [1].

Left atrial volume rather than left atrial dimension or size has traditionally been considered important [6,10-
14]. Recently, left atrial volume and function have been reported to be important for atrial fibrillation and left ventricular dysfunction [6,13,15-17]. Left atrial enlargement is common and is associated with various adverse cardiovascular outcomes, including atrial fibrillation and thromboembolic events $[13,18]$. Osnranek et al. reported that patients with a left atrial volume $>32 \mathrm{~mL} / \mathrm{m}^{2}$ had an almost 5-fold increased risk of postoperative atrial fibrillation after cardiac surgery [18]. Left atrial volume is a more robust marker of cardiovascular events than either left atrial area or diameter [15]. Left atrial enlargement can also be induced by acceleration of mitral valve pathology, a process known as left atrial remodeling. Left atrial remodeling leads to left atrial enlargement, left atrial dysfunction, and left atrial failure [6,7]. Recently, left atrial remodeling has also been associated with left ventricular diastolic dysfunction [19-21]. This process is commonly associated with pressure overload in mitral stenosis or volume overload in mitral regurgitation.

Mitral valve surgery has already been reported to induce left ventricular reverse remodeling and left atrial reverse remodeling $[2,17,22,23]$. However, factors predictive of mid- or long-term left atrial reverse remodeling after mitral valve surgery have not been clarified. This is the first report on the mid-term left atrial reverse remodeling after mitral valve surgery. Although we did not find any difference in mid-term survival or freedom from MACE, long-term follow-up studies are needed to prove that better clinical outcomes are associated with left atrial reverse remodeling. We also found a correlation between left atrial reverse remodeling and left ventricular reverse remodeling. The mechanisms by which reverse remodeling of the left atrium and left ventricle occur have not been clarified, and the relationship and correlation between left atrial and ventricular reverse remodeling have not been documented previously. There is no clear pathological explanation for our findings, and further studies are needed to clarify the mechanism responsible for this correlation.

Cho et al. studied left atrial reverse remodeling occurring immediately after mitral valve surgery [24]. They reported that a larger preoperative left atrial volume, mitral regurgitation rather than stenosis, younger age at the time of surgery, and sinus rhythm were predictive of left atrial reverse remodeling after mitral valve surgery. In comparison, our study supported the findings of younger age and larger preoperative left atrial volume being predictive of left atrial reverse remodeling, but we found no such association for sinus rhythm or mitral pathology.

Most patients with preoperative atrial fibrillation have already undergone significant left atrial remodeling before surgery (atrial enlargement has been considered a consequence of atrial fibrillation for at least 2 decades) 
[5]. The preoperative left atrial volume is thus significantly larger than normal in this patient group and so for these patients 2 preoperative factors, namely, preoperative rhythm and preoperative left atrial size, are strongly associated with each other. Reant et al. reported that restored sinus rhythm appears to be associated with left atrial reverse remodeling and reserved left ventricular diastolic function [25]. In our study, multivariate analysis eliminated the influence of preoperative rhythm. However, we still think that the preoperative sinus rhythm could be a preoperative predictor. However, we also believe that even patients with atrial fibrillation could have left atrial reverse remodeling if they have a large preoperative left atrial volume. Tsang noted that left atrial volume is an important predictor of cardiovascular events among patients with sinus rhythm, but not among patients with atrial fibrillation [15]. Our study suggests that, in patients with atrial fibrillation, mid-term left atrial reverse remodeling after mitral valve surgery could lead to better mid-term clinical outcomes.

Left atrial reverse remodeling after mitral repair has been reported by several authors [2,22,23]. Westenberg reported that restrictive annuloplasty for patients with dilated cardiomyopathy resulted in significant left atrial and left ventricular reverse remodeling [22]. Camterin et $a l$. reported on left atrial reverse remodeling early after mitral valve repair for mitral regurgitation [2]. They concluded that left atrial reverse remodeling is common and that a larger left atrium, lower blood pressure, and younger age preoperatively and lower trans-mitral mean pressure gradient and smaller residual mitral regurgitation postoperatively, were predictors of left atrial reverse remodeling [2]. Our findings support the predictive ability of a larger left atrium and younger age preoperatively and a lower trans-mitral mean pressure gradient postoperatively. Whether a procedure is performed for repair or replacement, and whether the preoperative diagnosis is mitral regurgitation or stenosis, could also be predictive of left atrial remodeling after mitral valve surgery.

\section{Limitation}

There were several limitations to the present study. This was a single-institution, non randomized, retrospective, observational clinical study. The sample size was small. We cannot, therefore, exclude a possible bias due to institutional standards or the patient population. Larger prospective studies are required to offset these limitations.

\section{Conclusion}

Age was the only predictor of mid-term left atrial reverse remodeling. There was a weak correlation between changes in LVDd and left atrial volume.

\section{REFERENCES}

[1] B. G. Song, Y. K. On, E. S. Jeon, J. H. Park, J. O. Choi, S. C. Lee, et al., "Ventricular Reverse Remodeling Early after Mitral Valve Repair for Severe Chronic Mitral Regurgitation with Atrial Fibrillation," Cardiology, Vol. 114, No. 2, 2009, pp. 132-141. doi:10.1159/000224770

[2] F. A. Canterin, C. C. Beladan, B. A. Popescu, C. Ginghina, A. C. Popescu, R. Piazza, et al., "Left Atrial Remodeling Early after Mitral Valve Repair for Degenerative Mitral Regurgitation,” Heart, Vol. 94, 2008, pp. 759-764. doi:10.1136/hrt.2007.122150

[3] A. M. Prichett, S. J. Jacobsen, D. W. Mahoney, R. J. Rodeheffer, K. R. Bailey and M. M. Redfirld, "Left Atrial Volume as an Index of Left Atrial Size: A PopulationBased Study," Journal of the American College of Cardiology, Vol. 41, No. 6, 2003, pp. 1036-1043. doi:10.1016/S0735-1097(02)02981-9

[4] D. Reed, R. D. Abbott, M. L. Smucker and S. Kaul, "Prediction of Outcomes after Mitral Valve Replacement in Patients with Symptomatic Chronic Mitral Regurgitation. The Importance of Left Atrial Size,” Circulation, Vol. 84, 1991, pp. 23-34. doi:10.1161/01.CIR.84.1.23

[5] A. J. Sanfilippo, V. M. Abascal, M. Sheehan, L. B. Oertel, P. Harrigan, R. A. Hughes, et al., "Atrial Enlargement as a Consequence of Atrial Fibrillation. A Prospective Echocardiographic Study," Circulation, Vol. 82, No. 3, 1990, pp. 792-797. doi:10.1161/01.CIR.82.3.792

[6] W. P. Abhayaratna, J. B. Seward, C. P. Appleton, P. S. Douglas, J. K. Oh, A. J. Tajik, et al., "Left Atrial Size. Physiologic Determinants and Clinical Applications," Journal of the American College of Cardiology, Vol. 47, No. 12, 2006, pp. 2357-2363. doi:10.1016/j.jacc.2006.02.048

[7] W. P. Abhayaratna, K. Fatema, M. E. Barnes, J. B. Seward, B. J. Gersh, K. R. Bailey, et al., "Left Atrial Reservoir Function as a Potent Marker for First Atrial Fibrillation or Flutter in Persons > 65 Years of Age," American Journal of Cardiology, Vol. 101, No. 11, 2008, pp. 16261629. doi:10.1016/j.amjcard.2008.01.051

[8] R. M. Lang, M. Bierig, R. B. Devereux, F. A. Flachskampf, E. Foster, P. A. Pellikka, et al., "Recommendations for Chamber Quantification: A Report from the American Society of Echocardiography's Guidelines and Standards Committee and the Chamber Quantification Writing Group, Developed in Conjunction with the European Association of Echocardiography, a Branch of the European Society of Cardiology," Journal of the American Society of Echocardiography, Vol. 18, No. 12, 2005, pp. 1440-1463. doi:10.1016/j.echo.2005.10.005

[9] P. Jiamsripong, T. Honda, C. S. Reuss, R. T. Hurst, H. P. Chaliki, D. E. Grill, et al., "Three Methods for Evaluation of Left Atrial Volume,” European Journal of Echocardiography, Vol. 9, No. 3, 2008, pp. 351-355.

[10] B. Kircher, J. A. Abbott, S. Pau, R. G. Gould, R. B. Himelman, C. B. Higgins, et al., "Left Atrial Volume Determination by Biplane Two-Dimensional Echocardiography: Validation by Cine Computed Tomography,” American Heart Journal, Vol. 121, No. 3, 1991, pp. 864-871. doi:10.1016/0002-8703(91)90200-2 
[11] O. Rodevan, R. Bjornerheim, M. Ljosland, J. Maehle, H. J. Smith and H. Ihlen, "Left Atrial Volumes Assessed by Three- and Two-Dimensional Echocardiography Compared to MRI Estimates," The International Journal of Cardiovascular Imaging, Vol. 15, No. 5, 1999, pp. 397410. doi:10.1023/A:1006276513186

[12] P. V. Maddukuri, M. L. Vieira, S. DeCastro, M. S. Maron, J. T. Kuvin, A. R. Patel, et al., "What Is the Best Approach for the Assessment of Left Atrial Size? Comparison of Various Unidimensional and Two-Dimensional Parameters with Three-Dimensional Echocardiographically Determined Left Atrial Volume," Journal of the American Society of Echocardiography, Vol. 19, 2006, pp. 1026-1032. doi:10.1016/j.echo.2006.03.011

[13] S. J. Lester, E. W. Ryan, N. B. Schiller and E. Foster, "Best Method in Clinical Practice and in Research Studies to Determine Left Atrial Size," American Journal of Cardiology, Vol. 84, No. 7, 1999, pp. 829-832. doi:10.1016/S0002-9149(99)00446-4

[14] H. Vyas, K. Jackson and A. Chenzbraun, "Switching to Volumetric Left Atrial Measurements: Impact on Routine Echocardiographic Practice," European Journal of Echocardiography, Vol. 12, No. 2, 2011, pp. 107-111. doi:10.1093/ejechocard/jeq119

[15] T. S. M. Tsang, W. P. Abhayaratna, M. E. Barnes, Y. Miyasaka, B. J. Gersh, K. R. Bailey, et al., "Prediction of Cardiovascular Outcomes with Left Atrial Size. Is Volume Superior to Area or Diameter?” Journal of the American College of Cardiology, Vol. 47, No. 5, 2006, pp. 1018-1023. doi:10.1016/j.jacc.2005.08.077

[16] A. A. Alsaileek, M. Osranek, K. Fatema, R. B. McCully, T. S. Tsang and J. B. Seward, "Predictive Value of Normal Left Atrial Volume in Stress Echocardiography," Journal of the American College of Cardiology, Vol. 47, No. 5, 2006, pp. 1024-1028. doi:10.1016/j.jacc.2005.09.069

[17] A. E. Topal, M. N. Eren and Y. Celik, "Left Ventricular and Left Atrium Remodeling after Mitral Valve Replacement in Case of Mixed Mitral Valve Disease of Rheumatic Origin,” Journal of Clinical Surgery, Vol. 25, No. 4, 2010, pp. 367-372. doi:10.1111/j.1540-8191.2010.01062.x

[18] M. Osranek, K. Fatema, F. Qaddoura, A. Al-Saileek, M.
E. Barnes, K. R. Bailey, et al., "Left Atrial Volume Predicts the Risk of Atrial Fibrillation after Cardiac Surgery," Journal of the American College of Cardiology, Vol. 48, No. 4, 2006, pp. 779-786. doi:10.1016/j.jacc.2006.03.054

[19] A. M. Prichett, D. W. Mahoney, S. J. Jacobsen, R. J. Rodeheffer, B. L. Karon and M. M. Redfield, "Diastolic Dysfunction and Left Atrial Volume. A Population-Bases Study," Journal of the American College of Cardiology, Vol. 45, No. 1, 2005, pp. 87-92. doi:10.1016/j.jacc.2004.09.054

[20] M. Matsuda and Y. Matsuda, "Mechanism of Left Atrial Enlargement Related to Ventricular Diastolic Impairment in Hypertension," Clinical Cardiology, Vol. 19, No. 12, 1996, pp. 954-959. doi:10.1002/clc.4960191211

[21] T. S. M. Tsang, M. E. Barnes, B. J. Gersh, K. R. Bailey and J. B. Seward, "Left Atrial Volume as a Morphophysiologic Expression of Left Ventricular Diastolic Dysfunction and Relation to Cardiovascular Risk Burden,” American Journal of Cardiology, Vol. 90, No. 12, 2002, pp. 1284-1289. doi:10.1016/S0002-9149(02)02864-3

[22] J. J. M. Westenberg, R. J. van der Geest, H. J. Lamb, M. I. M. Versteegh, J. Braun, J. Doornbos, et al., "MRI to Evaluate Left Atrial and Ventricular Reverse Remodeling after Restrictive Mitral Annuloplasty in Dilated Cardiomyopathy,” Circulation, Vol. 112, No. S1, 2005, pp. 437442.

[23] P. S. Dardas, A. A. Pitsis, D. D. Tsikaderis, N. E. Mezilis, P. N. Geleris and H. K. Boudoulas, "Left Atrial Volumes, Function and Work before and after Mitral Valve Repair in Chronic Mitral Regurgitation,” Journal of Heart Valve Disease, Vol. 13, No. 1, 2004, pp. 27-32.

[24] D. K. Cho, J. W. Ha, B. C. Chang, S. H. Lee, S. J. Yoon, C. Y. Shim, et al., "Factors Determining Early Left Atrial Reverse Remodeling after Mitral Valve Surgery,” American Journal of Cardiology, Vol. 101, No. 3, 2008, pp. 374-377. doi:10.1016/j.amjcard.2007.09.076

[25] P. Reant, S. Lafitte, P. Jais, K. Serri, R. Weerasooriya, M. Hocini, et al., "Reverse Remodeling of the Left Cardiac Chambers after Catheter Ablation after 1 Year in a Series of Patients with Isolated Atrial Fibrillation," Circulation, Vol. 112, 2005, pp. 2896-2903. 